\title{
The Political Economy of the (Weak) Enforcement of Indirect Taxes ${ }^{1}$
}

\author{
Martin Besfamille ${ }^{2} \quad$ Philippe De Donder ${ }^{3}$ \\ Jean-Marie Lozachmeur ${ }^{4}$
}

July 26, 2011

\footnotetext{
${ }^{1}$ We thank an anonymous referee, J. Alm, S. Auguste, R. Borck, W. Cont, H. Cremer, S. Eichfelder, E. Espino, L. Goerke, F. Navajas, L. Quesada, M. RaybaudiMassilia, C. Scartascini, M. Tommasi, seminar participants at FIEL, Toulouse School of Economics, Verona and Universidad Torcuato Di Tella, and attendants to the 2010 CESifo Area Conference on Public Sector Economics (Munich), $66^{\text {th }}$ Congress of the International Institute of Public Finance (Uppsala) and $14^{\text {th }}$ Meeting of the Latin American and Caribbean Economic Association (Buenos Aires) for very useful comments. Part of this paper has been written when M. Besfamille visited Toulouse School of Economics, whose hospitality is gratefully acknowledged. M. Besfamille also thanks financial support from Fondation Maison des Sciences de l'Homme (Hermes grant).

${ }^{2}$ Universidad Torcuato Di Tella. E-mail: mbesfamille@utdt.edu

${ }^{3}$ Toulouse School of Economics (GREMAQ-CNRS and IDEI). Corresponding author. E-mail: philippe.dedonder@tse-eu.fr

${ }^{4}$ Toulouse School of Economics (GREMAQ-CNRS and IDEI). E-mail: jeanmarie.lozachmeur@tse-eu.fr
} 


\begin{abstract}
The objective of this paper is to understand the determinants of the enforcement level of indirect taxation in a positive setting. We build a sequential game where individuals, who differ in their willingness to pay for a taxed good, vote over the enforcement level. Firms then compete à la Cournot and choose the fraction of sales taxes to evade. We assume in most of the paper that the tax rate is set exogenously. Voters face the following trade-off: more enforcement increases tax collection but also increases the consumer price of the goods sold in an imperfectly competitive market.

We obtain that the equilibrium enforcement level is the one most-preferred by the individual with the median willingness to pay, that it is not affected by the structure of the market (number of firms) and the firms' marginal cost, and that it decreases with the resource cost of evasion and with the tax rate. We also compare the enforcement level chosen by majority voting with the utilitarian level. In the last section, we endogenize the tax rate by assuming that individuals vote simultaneously over tax rate and enforcement level. We prove the existence of a Condorcet winner and show that it entails full enforcement (i.e., no tax evasion at equilibrium). The existence of markets with less than full enforcement then depends crucially on the fact that tax rates are not tailored to each market individually.
\end{abstract}

Key words: Tax evasion, imperfect competition, majority voting, intermediate preferences.

JEL Codes: D43, D72, H26, H32. 


\section{Introduction}

In many countries, indirect taxation raises a large fraction of aggregate tax proceeds. Evasion of indirect taxes such as VAT is then a crucial problem governments have to deal with. Nam, Parsche and Schaden (2001) present estimates for VAT evasion ${ }^{1}$ inside the European Union, between 1991 and 1993: their figures vary from $2.4 \%$ in the Netherlands to $20.2 \%$ in Greece, $22.6 \%$ in Spain and 34.5\% in Italy (see also Keen and Smith (2007) and European Commission (2009)). In developing countries, these estimates are, on average, higher: $29.6 \%$ for Argentina (AFIP (2008)), 35.3\% for Mexico (Hernández Trillo and Zamudio (2004)), and 54.8\% for Guatemala (SAT (2007)).

Tax evasion is affected among other things by enforcement policies. Such policies vary widely across countries. According to OECD (2009), the Australian Taxation Office (ATO) audits $8 \%$ of VAT registrants each year, compared to $20 \%$ for Her Majesty's Revenue \& Custom (HMRC) in the UK. Also, maximum sanctions for fraudulent reports differ significantly between these two countries: penalties may reach $50 \%$ of the amount of evaded tax in Australia, against 100\% in the UK. Although less public data is available, there is also evidence that tax enforcement varies across economic sectors within a given country. According to the French Cour des Comptes (2010), law, finance, insurance and health services firms were almost never audited in the Rhône-Alpes-Bourgogne region between 2003 and 2007. Anecdotal evidence suggests that in Argentina, the provincial Agencia de Recaudación de Buenos Aires (ARBA) does not audit VAT compliance of vegetables and meat retailers.

Cremer and Gavhari (1993) has shown that social optimality may call for differences in indirect tax enforcement policies between countries, or between economic activities in a given country. But the low aggregate enforcement level or the almost inexistent verifications in some economic sectors can hardly be explained by the normative theory of indirect tax enforcement policies. One possible explanation has been conjectured by Sandmo (2005, p. 660 ). He concludes his recent overview of the tax evasion literature by stating that "One perspective on tax evasion and the hidden economy that merits more attention is that of positive political economy. (...) It is also of major

\footnotetext{
${ }^{1}$ The figures represent estimations of amounts evaded, as percent of the potential VAT revenue, i.e. the revenue that would be obtained with full compliance.
} 
interest to achieve a better understanding of the political and economic forces that determine the policies that we actually observe. It is, e.g., not obvious that the low degree of enforcement of the tax law in some sectors or countries is entirely due to cost considerations; it may also be because the electorate is actually against attempts to achieve a higher rate of compliance."

The objective of this paper is precisely to provide a political economy analysis of why indirect tax enforcement levels vary across markets, and especially of why enforcement is low in certain markets. ${ }^{2}$ We assume that individuals vote over the enforcement level, anticipating perfectly the impact of their choice on market equilibrium. Voters face the following trade-off: more enforcement increases tax collection (and thus the amount of a uniform lump sum transfer) but also increases the consumer price of the goods sold in an imperfectly competitive market.

To our knowledge, and in accordance with Sandmo's statement above, the political economy determination of tax enforcement when firms evade indirect taxes has not been studied in the literature so far. More precisely, our paper constitutes a link between two strands of research. First, many articles deal with tax evasion by firms, under different market structures. Marelli (1984), Wang and Conant (1988) and Yaniv (1995) consider a risk-averse monopolist deciding simultaneously how much to produce and to evade. In particular, Yaniv (1995) presents the first rigorous analysis of the necessary conditions under which production is independent from evasion. Virmani (1989) and Cremer and Gahvari (1993) present models of risk-neutral firms that evade taxes under perfect competition. Virmani (1989) was the first to introduce concealment costs, as a way to reconcile the conventional framework with risk-neutral firms with Alligham and Sandmo (1972)'s paradigm of evasion under uncertainty. Marelli and Martina (1988), Goerke and Runkel (2006) analyze these same decisions in an imperfectly competitive environment. The papers closest to our are Bayer and Cowell (2006) and Goerke and Runkel (2011) who both study two-stage Cournot models, with risk-neutral firms deciding upon output and evasion while facing the risk of being audited. All these papers either concentrate on describing the equilibrium (evasion and production) behavior of firms and on performing a comparative statics analysis, or look at the firms's decisions from a normative perspective. None

\footnotetext{
${ }^{2} \mathrm{By}$ low or weak enforcement, we mean that little enforcement is taking place at equilibrium, and not necessarily that the equilibrium enforcement is lower than its optimal level.
} 
of these papers adopt a positive approach to enforcement decisions.

Our paper is also related to a very recent literature on political economy models of tax enforcement. These papers study majority voting over linear income taxes when tax evasion is possible. Their main objective is to understand how the equilibrium income tax rate is affected by the presence of tax evasion. Roine (2003) and Traxler (2006) stress that the decisive agent is the one with the median taxed income, who may differ from the individual with the median before-tax income if tax evasion opportunities are not monotone in pre-tax income. Borck (2004) shows that stricter enforcement may make redistributive taxation more attractive to the decisive voter. The presence of tax evasion may have a more drastic impact on the identity of the decisive voter and on the tax rate chosen by majority voting. Roine (2006) shows that introducing tax evasion may transform the classical conflict between rich and poor (where the median income individual is decisive) into an ends-against-the-middle situation where a coalition of poor and rich agents favor higher income tax rates. Borck $(2007,2008)$ shows that allowing for tax evasion may result in the non existence of a majority-voting income tax rate (because individual preferences over the tax rate are neither single-peaked nor single-crossing when tax evasion is introduced).

Our paper links these two strands of literature since it studies majority voting over the enforcement level when firms may evade indirect taxes. ${ }^{3}$ We consider a continuum of individuals characterized by their willingness to pay for a good which is subject to a sales tax. Since we focus on the determination of the enforcement level, we assume for most of the paper that the tax rate is set at an exogenous level and we solve the following three-stage model. In the first stage, individuals vote over the tax enforcement level. In the second stage, the good is produced in an imperfectly competitive market, where firms compete $a$ la Cournot. In the third stage, firms report to the government the amount of their sales. Firms decide either to conceal a fraction of their sales (at a resource cost) or to fully comply with the tax law, knowing that they will be audited and, if found to have evaded, penalized. In order to explain why equilibrium enforcement may be low, we bias the model in favor of full enforcement by assuming that government's audits are costless and perfect.

We solve the model backwards. In the last stage, each firm evades the same fraction of their sales. This fraction increases with the tax rate, de-

\footnotetext{
${ }^{3}$ From now on, we refer to these taxes as "sales taxes", but our analysis applies equally well to VAT.
} 
creases with the enforcement level but is independent of market variables such as the price of the good or the number of firms in the market. Anticipating this, in the second stage, firms compete $\grave{a}$ la Cournot. The equilibrium price depends positively upon the level of enforcement. Finally, we study the voting equilibrium at the first stage and we show that the equilibrium enforcement level corresponds to the one preferred by the consumer with the median willingness to pay. Performing the comparative static analysis of this level (assuming isoelastic demand functions) allows us to study its determinants, and to shed some light as to why this level may differ across markets. Surprisingly, we obtain that firms' marginal cost and market structure (the number of firms) have no influence on the equilibrium enforcement level. Enforcement is also negatively correlated with the resource cost of evasion and with the value of the tax rate. We also show that the comparison between majority chosen and socially optimal enforcement levels does not depend only on the distribution of willingness to pay (i.e., it is not simply a matter of comparing the median with the average willingness to pay).

We also study the simultaneous determination of the tax rate and of the enforcement level. We prove the existence of a majority voting equilibrium, even though the voting space is bidimensional. We show that the decisive voter should set the enforcement level high enough to discourage any tax evasion. In other words, the existence of low enforcement at equilibrium crucially depends on the fact that the tax rate is not chosen simultaneously by majority voting. We show how the chosen tax rate depends on the distribution of willingness to pay and on demand elasticity. We also show that, in our model with no redistribution motives (quasi-linear preferences) and no government revenue requirement, the socially optimal tax rate should be zero.

Our positive approach may be criticized on two accounts. First, one can object that people do not vote directly over enforcement levels. Direct majority voting is the simplest way to aggregate citizens preferences over the enforcement level. Any political economy mechanism (such as elections, lobbying, etc.) with the Condorcet winning enforcement level as equilibrium would give the same results as our simpler approach. Also, the enforcement level may be considered as a short-cut for more complex institutional decisions related to the efficiency of the tax authority (for instance, persistence of corrupt inspectors and lack of human or physical capital). Second, we concentrate on the demand side (consumers) while the supply side (firms) does not try to influence policy. An alternative approach would consider the 
supply side. We show below that profit is decreasing in enforcement in our symmetrical setting, so that firms' owners would vote/lobby against enforcement. A political-economy explanation of the differences in enforcement levels across markets would require heterogeneity of firms across markets. One route would be to study why it may be easier for firms to overcome the free-riding problem associated with lobbying in certain markets. One could then apply the results of Le Breton and Salanié (2003), and obtain that it is easier to lobby (and obtain a lower enforcement level) in markets where firms are heterogeneous. Another route would be to assume that some firms evade while others do not, so that some firms could actually benefit from enforcement because it would tilt the playing field in their favor. ${ }^{4}$ We leave this alternative approach to future research.

The remainder of this paper is organized as follows. The next section describes the model. Section 3 shows the equilibrium. Section 4 compares the voting equilibrium with the utilitarian optimal. Section 5 presents some comparative statics. Section 6 tackles the simultaneous determination by majority voting of the tax rate and the enforcement level. Section 7 studies various extensions to our model. All proofs appear in the Appendix.

\section{The model}

\section{$2.1 \quad$ Individuals}

There is a continuum of individuals of measure 1. Each individual has two sources of income: an exogenous endowment $w$ and a uniform lump sum transfer $G$ from the government. Individuals choose how much to consume of two goods, labelled 1 and 2. The price of good 1 is normalized to unity whereas the consumer price of good 2 is $p$. We denote by $x$ and $q$ the quantities bought of good 1 and 2 , respectively. Individuals are characterized by $\theta$, their willingness to pay for good 2. The parameter $\theta$ is distributed according to density $f(\theta)$ with cumulative distribution $F(\theta)$ on $[\underline{\theta}, \bar{\theta}]$. We denote the average value of $\theta$ by $\theta_{\mu}$ and its median by $\theta_{\text {med }}$. Utility of individual $\theta$ is

$$
U_{\theta}=x+\theta u(q)
$$

\footnotetext{
${ }^{4}$ We thank an anonymous referee for pointing out these alternative explanations.
} 
where the function $u$ is strictly increasing and concave, verifying the Inada conditions. ${ }^{5}$

Individual $\theta$ takes the lump sum transfer $G$ as given and chooses the quantity $q$ that maximizes his utility (1) subject to the individual's budget constraint

$$
x \leq G+w-p q .
$$

The first-order condition ${ }^{6}$

$$
\theta u^{\prime}(q)=p
$$

defines $q_{\theta}(p)$, the demand for good 2. Aggregate demand for good 2 is given by

$$
Q(p)=\int_{\underline{\theta}}^{\bar{\theta}} q_{\theta}(p) f(\theta) d \theta .
$$

\subsection{The industry}

We do not explicitly formalize the market for the numeraire good. Good 2 is produced by $n$ identical, risk neutral firms labelled $i=1, \ldots, n$. The number of firms is exogenous, so that we cover all situations, from monopoly $(n=1)$ to perfect competition $(n \rightarrow \infty)$. Each firm $i$ simultaneously decides how much to produce $\left(q_{i}\right)$. Firms have constant returns to scale technologies, with the same marginal cost $c>0$. Given output decisions $\left(q_{1}, \ldots, q_{n}\right)$, the price adjusts to the level that clears the market. We denote by $p(Q)$ the inverse market demand, where $Q=\sum_{i} q_{i}$ is aggregate output. The function $p(Q)$ is twice-continuously differentiable, with $p^{\prime}(Q)<0$ at all $Q$.

Each firm $i$ has to pay a sales tax at a constant proportional rate $0<$ $\tau<1$. We assume that the sales amount $p q_{i}$ is private information, and that taxes due are computed based on the amount of sales reported by the firm. We denote by $e_{i} \in[0,1]$ the fraction of sales that firm $i$ fails to report. If $e_{i}=0$, the firm fully complies with the tax law. But if $e_{i}>0$, we say that there is tax evasion. We follow Cremer and Gahvari (1993) by assuming that,

\footnotetext{
${ }^{5}$ This approach, where individuals differ in their willingness to pay for a good and are endowed with a quasi-linear utility, is standard in the industrial organization literature. Observe that our results would not be affected if endowments were heterogeneous across individuals. In section 7 we discuss how our results would change if preferences were not quasi-linear and agents had different incomes, which is the framework often used in public economics.

${ }^{6}$ We assume that each individual's exogenous endowment is large enough so that the amount consumed of good 2 satisfies this first-order condition.
} 
in order to be successful, concealment of the fraction $e_{i}$ entails a cost of $g\left(e_{i}\right)$ per $\$$ of sale.

We assume the following functional specification

$$
g\left(e_{i}\right)=k \frac{e_{i}^{2}}{2}
$$

where the parameter $k \geq 1$ reflects the (in)efficiency of the evasion technology. $^{7}$

We assume that profits are distributed to unmodelled non-resident agents. We come back to this assumption in sections 4 and 7 .

\subsection{The government}

The government audits each firm $i$ with the same probability $a \in(0,1)$. When a firm is not audited, it pays sales taxes based on the amount reported - i.e., it pays $\tau\left(1-e_{i}\right) p q_{i}$. We assume that audits are costless and perfect, so that the government identifies the true sales amount of audited firms with certainty. Observe that this assumption biases the model in favor of high or full tax enforcement while our objective is to explain how equilibrium enforcement may be low. If under-reporting of sales is detected, the evading firm has to pay the tax that it legally owes, $\tau p q_{i}$ plus an additional fine, which is a fraction $\lambda>0$ of the amount of taxes evaded. Our modelling is in line with the US legislation - see Skinner and Slemrod (1985). With all revenues collected (taxes and fines), the government finances the provision of the lump sum transfer $G$.

\section{$2.4 \quad$ Timing}

Up to section 6 , we assume that the tax rate has been set at the exogenous rate of $\tau$ before the beginning of the game. The timing of the game we study runs sequentially as follows.

1. Individuals vote over the level of tax enforcement.

2. Firms compete à la Cournot in the market.

\footnotetext{
${ }^{7}$ Our results would carry through with a generic increasing and convex concealment cost function satisfying $g(0)=0$. Our functional specification allows to perform more easily comparative statics analysis.
} 
3. Firms decide the fraction of sales to report.

4. The government audits firms, collects taxes and fines due and finances the lump sum transfer out of the total tax and fines proceeds.

The assumption that firms decide the fraction of sales to report after having competed in the market is made for expositional convenience: all our results would carry through if the output and evasion decisions were taken simultaneously (or if evasion decisions were carried first).

In section 6 , we endogenize $\tau$ and analyze the simultaneous determination of the tax rate and the enforcement level.

\section{Equilibrium of the model}

As is usual, we solve the game backwards. As the last stage is purely mechanical and involves no optimization, we start with the penultimate one.

\subsection{Evasion}

In stage 3 , each firm $i$ chooses the level of evasion $e_{i}^{*}$ that maximizes its expected profit

$$
\mathbb{E} \Pi_{i}=a \Pi_{i}^{A}+(1-a) \Pi_{i}^{N A}
$$

where

$$
\Pi_{i}^{A}=\left[p(Q)\left(1-\tau\left(1+\lambda e_{i}\right)-g\left(e_{i}\right)\right)-c\right] q_{i}
$$

and

$$
\Pi_{i}^{N A}=\left[p(Q)\left(1-\tau\left(1-e_{i}\right)-g\left(e_{i}\right)\right)-c\right] q_{i} .
$$

denote ex-post profits when firm $i$ is (respectively, is not) audited. Therefore, expected profit is

$$
\mathbb{E} \Pi_{i}=\left[p(Q)\left(1-\tau\left(1-e_{i}(1-\xi)\right)-g\left(e_{i}\right)\right)-c\right] q_{i},
$$

where $\xi=a(1+\lambda)$ denotes the expected payment rate on undeclared sales tax, expressed as a proportion of the tax rate $\tau$. From now on, $\xi$ will be our measure of tax enforcement.

The following first-order condition

$$
\frac{\partial \mathbb{E} \Pi_{i}}{\partial e_{i}}=\left[\tau(1-\xi)-g^{\prime}\left(e_{i}\right)\right] p(Q) q_{i}=0
$$


characterizes the optimal fraction $e_{i}^{*}$ in case of an interior solution. Throughout the paper, we denote equilibrium values of variables with a * At an interior optimum, each firm declares a fraction of sales such that the marginal expected net benefit from evading this fraction equals the marginal cost of concealing it. Observe that $e_{i}^{*}$ is independent of the market structure (the number of firms $n$ ), of the firms' cost $c$ and of the variables determined in the market (price and quantities). ${ }^{8}$ Moreover, as all firms are audited with equal probability, they all evade the same fraction of sales taxes. From now on, we save on notation by eliminating the subscript $i$ each time a variable has the same value for all firms. Using the functional form adopted for the concealment costs function, we obtain an explicit solution for the optimal evaded share $e^{*}$. We gather the results in the following proposition.

Proposition 1 When $\xi<1$, each firm fails to report a fraction of sales $e^{*}=\tau(1-\xi) / k$. This fraction increases with the tax rate $\tau$ and decreases with enforcement $\xi$ and with the inefficiency of the evasion technology $k$. When $\xi \geq 1$, no firm evades.

In order to evade, a firm must face an expected rate of payment on undeclared sales that is lower than the tax itself. If this is not the case, there is no evasion at equilibrium.

We now move to the second stage of the game.

\subsection{Market competition}

Substituting the optimal evasion share $e^{*}$ into the expected profit function (3) we obtain

$$
\mathbb{E} \Pi_{i}=\left[p(Q)\left(1-\tau^{e}-g\left(e^{*}\right)\right)-c\right] q_{i},
$$

where $\tau^{e}$ denotes the effective tax rate paid by firms. The legal tax rate $\tau$ is modified by incorporating the evasion decision and the expected fine paid on the amount evaded:

$$
\tau^{e}=\tau\left(1-e^{*}(1-\xi)\right)
$$

Observe that

$$
\tau^{e}+g\left(e^{*}\right)=\tau-\frac{\tau^{2}(1-\xi)^{2}}{2 k}<\tau \text { when } \xi<1,
$$

\footnotetext{
${ }^{8}$ Cremer and Gahvari (1993) obtain the same independence result.
} 
so that evasion allows firms to increase the fraction of their sales that they retain. Straightforward differentiation shows that

$$
\frac{\partial \tau^{e}}{\partial \xi}=\tau[\underbrace{e^{*}}_{\text {Enforcement effect }}-\underbrace{\frac{\partial e^{*}}{\partial \xi}(1-\xi)}_{\text {Evasion effect }}]>0 .
$$

The effective tax rate increases with enforcement through two channels: a direct "enforcement effect" (that increases the expected payment rate on undeclared sales) and an indirect "evasion effect" (that decreases the fraction of sales undeclared).

Each firm chooses $q_{i}$ in order to maximize its expected profit, taking as given the decisions of all other firms $j \neq i$. The first-order condition for firm $i$ is given by

$$
\frac{\partial \mathbb{E} \Pi_{i}}{\partial q_{i}}=\left[1-\tau^{e}-g\left(e^{*}\right)\right]\left[p(Q)+p^{\prime}(Q) q_{i}^{*}\right]-c=0,
$$

from which we see that, in order to obtain an interior solution, $p(Q)+$ $p^{\prime}(Q) q_{i}^{*}>0$. Existence and uniqueness of the Cournot equilibrium are ensured if we also assume

$$
\frac{\partial^{2} \mathbb{E} \Pi_{i}}{\partial q_{i} \partial q_{j}}=\left[1-\tau^{e}-g\left(e^{*}\right)\right]\left[p^{\prime}(Q)+q_{i} p^{\prime \prime}(Q)\right]<0, i \neq j,
$$

i.e., the marginal revenue of firm $i$ is decreasing in any other firm $j$ 's production (see Vives (1999)). With this assumption, the second-order condition $\partial^{2} E \Pi_{i} / \partial q_{i}^{2}=\left[1-\tau^{e}-g\left(e^{*}\right)\right]\left[2 p^{\prime}(Q)+p^{\prime \prime}(Q) q_{i}^{*}\right] \leq 0$ automatically holds.

Since firms are identical, the equilibrium production decisions $q_{i}^{*}$ are the same. We sum the first-order conditions over the $n$ firms and obtain

$$
\left[1-\tau^{e}-g\left(e^{*}\right)\right]\left[n p(Q)+p^{\prime}(Q) Q^{*}\right]=n c .
$$

This equality implicitly defines the equilibrium aggregate output $Q^{*} .{ }^{9}$ Dividing by $p$ and rearranging, we finally obtain

$$
\frac{p^{*}-\tilde{c}}{p^{*}}=\frac{1}{n \eta}
$$

\footnotetext{
${ }^{9}$ As the market equilibrium is symmetric and both the number of firms and the prevailing price are observable, the tax authority could in theory infer sales per firm and thus whether evasion has taken place. We assume that audits are necessary to prove evasion - i.e., although sales can be infered in equilibrium, evasion is not verifiable unless audits are commissioned.
} 
where $p^{*}=p\left(Q^{*}\right), \eta$ is the (absolute value of the) price elasticity of demand and

$$
\tilde{c}=\frac{c}{1-\tau^{e}-g\left(e^{*}\right)} .
$$

Equation (4) is the usual inverse-elasticity rule, where $\tilde{c}$ represents the effective marginal cost paid by firms. It is easy to see that $\tilde{c}>c$ when $\tau>0$ and that $\tilde{c}$ increases with $\tau$ and with $\xi$ : taxation is equivalent to an increase in the marginal cost faced by the firm, but evasion allows to dampen in part this impact. As is intuitive, $p^{*}$ increases with $\tilde{c}$. Observe that a more competitive industry (i.e., a larger value of $n$ ) results, other things equal, in a lower mark-up over the marginal cost $\tilde{c}$, but does not impact this marginal cost. Since $Q^{*}$ and thus $p^{*}$ are continuous functions of the enforcement parameter $\xi$, straightforward use of the implicit function theorem allows us to obtain the following proposition:

Proposition 2 When $\xi<1$, the equilibrium price $p^{*}$ increases with the enforcement level $\xi$. When $\xi \geq 1, p^{*}$ is independent of $\xi$.

As mentioned above, evasion helps firms attenuate the impact of taxation on their marginal cost. Hence, with evasion, the consumer price is lower than the level that would have prevailed with full compliance. Therefore, the higher the enforcement, the lower the evasion and thus the higher is the equilibrium price level.

\subsection{Voting over the tax enforcement level}

We are now in a position to solve for the first stage decision, by majority voting, of the tax enforcement level $\xi$. Making use of the individual's budget constraint (2) and of the equilibrium price (4) into the utility function (1), we obtain the indirect utility ${ }^{10}$ of individual $\theta$ :

$$
V_{\theta}=w-p^{*} q_{\theta}\left(p^{*}\right)+\theta u\left(q_{\theta}\left(p^{*}\right)\right)+G .
$$

One way to prove the existence of a Condorcet winning value of $\xi$ (i.e., a value of $\xi$ that is preferred by a majority of citizens to any other value)

\footnotetext{
${ }^{10}$ Recall that firms' profits are distributed to non-residents. Alternatively, we could assume that firms' owners are resident but that they represent a set of measure zero without affecting this section's results.
} 
consists in checking that individual preferences described by equation (6) satisfy the single-crossing property in the $(\xi, G)$ space. Using the envelope theorem, we obtain that the marginal rate of substitution in the $(\xi, G)$ space is given by

$$
M R S(\xi, G)=-\frac{\partial V_{\theta} / \partial \xi}{\partial V_{\theta} / \partial G}=p^{* \prime}(\xi) q_{\theta}\left(p^{*}\right)>0 .
$$

Intuitively, since more tax enforcement increases the consumer price of the good, agents have to be compensated with a larger transfer.

Indifference curves are single-crossing since

$$
\begin{aligned}
\frac{\partial M R S(\xi, G)}{\partial \theta}=p^{* \prime}(\xi) \frac{\partial q_{\theta}\left(p^{*}\right)}{\partial \theta} & >0 \text { if } \xi<1 \\
& =0 \text { if } \xi \geq 1
\end{aligned}
$$

The intuition for this result is straightforward: since higher $\theta$ individuals consume more of the good, they need more compensation following a tax enforcement-induced price increase (except if the enforcement is already so high that it has no impact on the price anymore).

We then apply the median voter theorem (see Gans and Smart (1996)) and obtain the following result.

Proposition 3 The Condorcet winning tax enforcement level, denoted by $\hat{\xi}$, corresponds to the preferred level of enforcement of the individual with the median value of $\theta$.

We denote by $\xi^{*}(\theta)$ individual $\theta$ 's preferred value of $\xi$, so that $\hat{\xi}=$ $\xi^{*}\left(\theta_{\text {med }}\right)$. Using an envelope argument, $\xi^{*}(\theta)$ is given by the following firstorder condition:

$$
-p^{* \prime}(\xi) q_{\theta}\left(p^{*}\right)+G^{\prime}(\xi)=0 .
$$

The first term describes the impact of an increase in $\xi$ on individual $\theta$ 's expenditure, through an increase in $p^{*}$. Expenditure in good 2 increases, which is detrimental to the individual's utility. The second term shows the impact on $G$, and is obtained by differentiating the government's budget constraint:

$$
G=\tau^{e} p^{*} Q\left(p^{*}\right)
$$

Equation (8) shows that tax proceeds $G$ can be expressed as the product of two terms: the effective tax rate $\tau^{e}$ and the actual value of sales, $p^{*} Q\left(p^{*}\right)$. Therefore, an increase in the enforcement level $\xi$ has two effects on the value 
of $G$. First, the effective tax rate increases, as explained in section 3.2. Second, due to the change in $p^{*}$, the actual value of sales changes. One can surmise that the elasticity of demand will play a crucial role in determining the sign of this second impact.

Observe that condition ( 7 ) does not require $G$ to be globally concave in $\xi$, but that it implies that $G^{\prime}(\xi)>0$ at $\xi^{*}(\theta)$ - i.e., we are on the upward sloping side of the "Laffer curve" $G(\xi)$. This is intuitive, since increasing tax enforcement has the drawback of increasing the consumer price $p^{*}$, and is thus only palatable to consumers if it increases the lump sum transfer that they receive.

We know from Milgrom and Shannon (1994, Theorem 4) that the singlecrossing property implies that the most-preferred enforcement level is monotone with respect to $\theta$, so that

$$
\operatorname{sgn}\left(\frac{\partial \xi^{*}(\theta)}{\partial \theta}\right)=\operatorname{sgn}\left(-p^{* \prime}(\xi) \frac{\partial q_{\theta}\left(p^{*}\right)}{\partial \theta}\right)<0,
$$

i.e., individuals with a higher willingness to pay (who consume more of the good than individuals with a weaker taste for the good, at any given price) favor less tax enforcement as a mean to decrease the equilibrium price of the good.

\section{Normative analysis of the voting equilib- rium}

We now compare the tax enforcement level chosen by majority voting, $\widehat{\xi}$, with the level that would be chosen by a benevolent social planner. It is important to keep the timing of the game unchanged to do a proper comparison: the value of $\xi$ is chosen at the first stage and then the game proceeds in the same sequence as previously. We adopt the usual utilitarian definition of welfare, given by

$$
\mathcal{W}=w+\int_{\underline{\theta}}^{\bar{\theta}}\left[\theta u\left(q_{\theta}\left(p^{*}\right)\right)-p^{*} q_{\theta}\left(p^{*}\right)\right] f(\theta) d \theta+G,
$$

where $G$ is given by (8). Observe that we do not include firms' profits in our definition of welfare. We do this in order not to bias the comparison with the tax enforcement level chosen by majority voting, since individuals do not take profits into account when voting. We rationalize this formulation by 
assuming that profits are paid to the non-resident owners of the firm. We come back to this assumption in section 7 .

We prove the following proposition in the Appendix.

Proposition 4 The optimal enforcement level $\xi^{\text {opt }}$ is lower than $\widehat{\xi}$ if the demand of the $\theta_{\text {med }}$ individual, $q_{\theta_{\text {med }}}\left(p^{*}(\hat{\xi})\right)$, is larger than the average demand, $Q\left(p^{*}(\hat{\xi})\right)$. Otherwise, the opposite relationship between $\hat{\xi}$ and $\xi^{\text {opt }}$ occurs.

Observe that the comparison between equilibrium and optimum enforcement levels hinges on the difference between the demand of the median type $q_{\theta_{\text {med }}}$ and the average demand $Q$ (rather than the demand of the average individual $q_{\theta_{\mu}}$ ). The intuition for this Proposition is straightforward once we recall from (9) that individuals with a larger willingness to pay (and thus a larger demand) prefer a lower enforcement level in order to bring down the price of good 2. The identity of the type with the average demand is of course endogenous to the model, and may depend upon other determinants than the distribution function $F$ (such as, for instance, the price elasticity of demand). We then need to introduce functional forms in order to draw more specific results.

\section{Comparative static analysis}

In this section, we analyze the impact of changes in parameters of the model upon the enforcement levels $\widehat{\xi}$ and $\xi^{o p t}$. There are three reasons why such an exercise is meaningful and relevant. First, it allows to obtain testable implications, for instance on which variables affect the fraction of sales taxes evaded, which is the measure on which the empirical literature has focused (see Introduction). Second, it allows to compare equilibrium and optimum enforcement levels/fractions of sales tax evaded, shedding light on which markets may exhibit too much or too little (from a social viewpoint) evasion. Last but not least, it allows us to answer the main question raised by this paper: why is it that certain markets exhibit less enforcement than others?

To perform this comparative static analysis, we need to impose functional forms. From now on, we restrict ourselves to utilities given by

$$
u(q)=\frac{q^{1-\sigma}}{1-\sigma}
$$


where $1 / \sigma>0$ denotes the constant (absolute value of the) price elasticity of demand. We report in the Appendix the individual and aggregate demands, as well as the equilibrium price.

Using equation (8), the first-order condition (7) that characterizes the (interior) equilibrium $\xi$ of an individual of type $\theta$ can be written as

$$
\tau e^{*} p^{*} Q\left(p^{*}\right)[\underbrace{2+(1-1 / \sigma) \frac{\tilde{c}}{c} \tau^{e}}_{A}-\underbrace{-\frac{\tilde{c}}{c}\left(\frac{\theta}{\theta_{M}}\right)^{1 / \sigma}}_{B}]=0,
$$

or alternatively as

$$
\xi^{*}(\theta)=1-\sqrt{\frac{k\left[\left(\frac{\theta}{\theta_{M}}\right)^{1 / \sigma}+(1+1 / \sigma) \tau-2\right]}{(1 / \sigma) \tau^{2}}},
$$

where $\theta_{M}$ denotes the type with the average demand. The Condorcet winning enforcement level $\widehat{\xi}$ corresponds to $\xi^{*}\left(\theta_{\text {med }}\right)$, while the optimal level $\xi^{o p t}$ is given by $\xi^{*}\left(\theta_{M}\right)$.

We first study the comparative statics of the variables which do not affect $\theta_{M}$ nor $\theta_{\text {med }}$. The sign of their impact on $\widehat{\xi}$ and $\xi^{\text {opt }}$ is the same, according to $(12)$.

Proposition 5 Assume that individual utilities are isoelastic. The majority chosen and the optimal enforcement levels depend neither upon the marginal cost $c$ nor the number of firms $n$. Both enforcement levels always decrease with the inefficiency of the evasion technology $k$, and also with the tax rate $\tau$ when the demand elasticity $1 / \sigma$ is lower than one.

To understand this proposition, recall from $(7)$ that $\xi^{*}(\theta)$ balances the marginal impact of the enforcement level on the individual's expenditures (term $B$ in (11)) and on the government's transfer (term $A$ in (11)). Both the marginal cost $c$ and the number of firms $n$ impact only the amount of sales evaded. Since this amount plays the same multiplicative role with respect to both effects $A$ and $B$ in (11), they do not affect $\xi^{*}(\theta)$. The impact of the evasion cost $k$ is more interesting. The sensitivity of the price $p^{*}$ to $\xi$ increases with $k$, which increases the impact of $\xi$ on type $\theta$ 's expenditure and 
calls for a smaller most-preferred $\xi$. On the other hand, increasing $k$ amplifies the effect of $\xi$ on aggregate sales volumes, which determine the transfer from the government. Even though the sign of this impact depends on the demand elasticity (it calls for a larger value of $\xi$ if the demand elasticity is smaller than one), equation (12) shows that the first impact is always larger than the second, so that $\xi^{*}(\theta)$ decreases with $k$.

Increasing the tax rate $\tau$ also has two similar impacts. First, it increases the sensitivity of type $\theta$ 's expenditure to $\xi$, calling for a smaller most-preferred value of $\xi$. Second, it affects the sensitivity of the sales values to $\xi$. As with $k$, the sign of this second impact depends upon the value of the demand elasticity. When demand is inelastic $(1 / \sigma \leq 1)$, both effects reinforce each other and call for a smaller $\xi^{*}(\theta)$. Straightforward but tedious manipulations of (12) show that $\xi^{*}(\theta)$ decreases with $\tau$ for most (but not all) values $\tau$ and distributions of $\theta$ even when $1 / \sigma>1^{11}$

It is interesting to observe how the equilibrium fraction of sales evaded is affected by these variables. Recalling that $e^{*}=\tau(1-\xi) / k$, we obtain the following Corollary to Proposition 5:

Corollary 1 Assume that individual utilities are isoelastic. The fraction of sales evaded at the majority chosen and the optimal enforcement levels depends neither upon the marginal cost $c$ nor the number of firms $n$. The fraction of sales evaded at both enforcement levels always decreases with the inefficiency of the evasion technology $k$, and increases with the tax rate $\tau$ when the demand elasticity $1 / \sigma$ is lower than one.

The comparative statics results of $c, n$ and $\tau$ on the fraction of sales evaded are straightforward given their impact on $\hat{\xi}$ and $\xi^{o p t}$. The impact of $k$ is more convoluted, since a larger $k$ decreases $e^{*}$ for a given $\xi$, but also decreases $\xi^{*}(\theta)$ which leads to a larger $e^{*}$. We obtain that the direct impact of $k$ on $e^{*}$ is larger than the indirect impact through $\xi^{*}(\theta)$, leading to a smaller fraction of sales evaded when $k$ increases.

We now move to the impact of two elements which affect both the identity of the decisive individuals $\left(\theta_{\text {med }}\right.$ and/or $\left.\theta_{M}\right)$ together with their preferences

\footnotetext{
${ }^{11}$ Three inequalities must be simultaneously satisfied to have $\partial \xi^{*}(\theta) / \partial \tau>0$ : the first two are given by (17) in the proof of Proposition 5 in the Appendix and guarantee that $0<\xi^{*}(\theta)<1$, while the third one, $\alpha \tau+2\left(\left(\theta / \theta_{M}\right)^{1 / \sigma}-2\right)>0$ (where $\alpha=1+1 / \sigma$ ), guarantees that the derivative of (12) with respect to $\tau$ is positive. It is far from easy to find parameters that satisfy these three equations simultaneously.
} 
for $\xi$, namely the price elasticity of the demand function, $1 / \sigma$, and the taste distribution function $F$. The demand elasticity decreases the impact of $\xi$ on $G$ through the variation in the value of actual sales, calling for a lower value of $\xi^{o p t}$. The intuition for this result is reminiscent of the Ramsey argument for the setting of indirect taxes: increasing $\xi$ raises the effective tax rate paid by firms, which is more detrimental to welfare when the tax base is very elastic. The impact of the demand elasticity $1 / \sigma$ on the majority chosen enforcement level $\hat{\xi}$ is more complex, although the identity of the decisive type $\theta_{\text {med }}$ is not affected by $1 / \sigma$. This is due to the fact that increasing the demand elasticity has a second effect beyond the one identified above when $\theta_{\text {med }} \neq \theta_{M}$, namely to affect type $\theta_{\text {med }}$ 's expenditures. Since the sign of this impact is ambiguous, we can not sign the impact of $1 / \sigma$ over the majority chosen enforcement level. We resort to numerical simulations based on the following assumption.

Assumption 1: The taste parameter $\theta$ is distributed according to a $\operatorname{Beta}(a, b)$ function over $[0,2]$ with $(a=2, b \in[2,5]),(a \in[2,5], b=2)$ and $\sigma \in[1 / 2,3 / 2]$. Observe that the density is symmetric when $a=b$, and that its degree of skewness increases with $b$ and decreases with $a$. Skewness is positive when $a<b$ and negative when $a>b$.

Under Assumption 1, we obtain that markets with a larger demand elasticity exhibit lower equilibrium enforcement levels (and thus a larger fraction of taxes evaded). We also obtain numerically that $\theta_{M}$ increases with the elasticity, so that the ratio $\theta_{\text {med }} / \theta_{M}$ decreases (since $\theta_{\text {med }}$ is not affected by $1 / \sigma$ ). This means that, other things being equal, the majority-chosen enforcement level will be too large (resp., too small) from a welfarist viewpoint in markets with a high (resp., low) demand elasticity.

We finally study the impact of the taste distribution $F$ on the enforcement level. As for the majority chosen enforcement level $\hat{\xi}$, it depends upon the quotient $\theta_{\text {med }} / \theta_{M}$, where both terms are affected by $F$ (observe from (16) in the Appendix that the whole distribution matters, and not only the comparison of the median with the average willingness to pay). Using numerical simulations based on Assumption 1, we obtain that $\theta_{\text {med }} / \theta_{M}$ decreases with the skewness of the taste distribution, so that the majority chosen enforcement level increases. This is intuitive since an increase in the skewness means that a larger mass of individuals have low values of $\theta$. Those individuals buy less of the good, while receiving the same lump sum transfer as the others. They are then less sensitive to an enforcement-induced increase of the con- 
sumer price of the good and thus favor a higher value of the enforcement level. Since the optimal enforcement level is not affected by the skewness of the distribution (see equation (12) with $\theta=\theta_{M}$ ), we also obtain that the majority chosen enforcement level is larger (resp., smaller) than optimal in markets where the skewness of the taste parameter distribution is large (resp., low).

We summarize those results in the following Proposition.

Proposition 6 Assume that individual utilities are isoelastic and that the distribution of the taste parameter $\theta$ follows Assumption 1. The demand price elasticity decreases both the majority chosen and the optimal enforcement levels. The majority chosen enforcement level is larger than optimal if the demand elasticity is large enough. The skewness of the distribution function $F$ does not affect the optimal enforcement level but increases its majority chosen level, which becomes larger than optimal when the skewness is large enough.

The impact of both the demand elasticity and the skewness of $F$ on the fraction of sales evaded is straightforward, since neither appears directly in $e^{*}=\tau(1-\xi) / k$. We then obtain the testable implications that the demand elasticity increases the equilibrium fraction of sales tax evaded, while the skewness of the taste distribution decreases it (provided that preferences are isoleastic and satisfy Assumption 1).

Propositions 5 and 6 allow us to shed light on the characteristics of markets where the enforcement level is low, either in absolute term or compared with its optimal utilitarian level. Consider separate markets, with the same tax rate set exogenously across markets, but with the enforcement level chosen separately on each market. Neither the degree of competition on each market (as measured by the number of firms) nor the firms' efficiency (measured by their marginal cost) does explain differences in (majority chosen or optimum) enforcement levels. A low majority chosen enforcement level can result from a large concealment cost (in which case the fraction of taxes evaded will also be low), a small demand elasticity or a low degree of skewness of the taste distribution. The latter two cases also characterize the markets where the majority chosen enforcement level is lower than optimal. Finally, if tax rates vary exogenously across markets ${ }^{12}$ that are otherwise similar, then

\footnotetext{
${ }^{12}$ This is frequent in Europe, where most countries apply a reduced (circa 5\%) VAT rate for certain goods. This is also the case in many US states, with sales tax rates varying across products.
} 
Proposition 5 suggests a negative correlation between tax rate and (majority chosen or optimal) enforcement levels (provided that the demand elasticity is low enough).

We stress that all these results assume that the tax rate $\tau$ is a parameter of the model -i.e., that it is set at an exogenous level before the beginning of the game. We now endogenize the choice of $\tau$ as well.

\section{Simultaneous voting}

We now turn to the simultaneous determination of both the tax rate $\tau$ and the enforcement level $\xi$ by majority voting. It is well known that a Condorcet winner (i.e., a pair $(\tau, \xi)$ preferred by a majority of voters to any other pair) often fails to exist when voting simultaneously on more than one policy dimension.

In the context of our model, where voters differ according to only one dimension (the intensity of their preference for the good, measured by the parameter $\theta$ ), a sufficient condition for the existence of a Condorcet winning pair $(\tau, \xi)$ is that utilities satisfy the Intermediate Preferences property.

Definition: Preferences are called intermediate if they can be expressed as

$$
V(\theta, \tau, \xi)=J(\tau, \xi)+K(\theta) H(\tau, \xi),
$$

where $K(\theta)$ is monotone in $\theta$ and where the functions $J(\tau, \xi)$ and $H(\tau, \xi)$ do not depend on $\theta$.

When preferences are intermediate, the Condorcet winning pair $(\tau, \xi)$ corresponds to the preferred pair of the individual with the median willingness to pay for the good, $\theta_{\text {med }}$ (see Grandmont (1978), Persson and Tabellini (2000)).

In order to check whether preferences are intermediate, we keep the isoelastic formulation. Starting with the indirect utility function

$$
V(\theta, \tau, \xi)=w-p q_{\theta}\left(p^{*}\right)+\theta u\left(q_{\theta}\left(p^{*}\right)\right)+G,
$$

where $p^{*}$ and $G$ are functions of $\tau$ and $\xi$ and replacing $q_{\theta}\left(p^{*}\right)$ by its explicit expression, we obtain

$$
\begin{aligned}
V(\theta, \tau, \xi) & =w-p^{*}\left(\frac{\theta}{p^{*}}\right)^{1 / \sigma}+\theta \frac{\left(\theta / p^{*}\right)^{(1-\sigma) / \sigma}}{1-\sigma}+G \\
& =w+p^{* \frac{\sigma-1}{\sigma}} \theta^{\frac{1}{\sigma}} \frac{\sigma}{1-\sigma}+G .
\end{aligned}
$$


Clearly, preferences are intermediate, with $K(\theta)=\theta^{\frac{1}{\sigma}} \frac{\sigma}{1-\sigma}, H(\tau, \xi)=p^{* \frac{\sigma-1}{\sigma}}$ and $J(\tau, \xi)=G .^{13}$ We then have proved that ${ }^{14}$

Proposition 7 With isoelastic utilities, a Condorcet winning pair $(\tau, \xi)$ exists and corresponds to the preferred pair of the individual with $\theta=\theta_{\text {med }}$.

We now compute the expression for the most-preferred pair of type $\theta$, denoted by $\left(\tau^{\circ}(\theta), \xi^{\circ}(\theta)\right)$. We show in the appendix that the most-preferred pair $\left(\tau^{\circ}(\theta), \xi^{\circ}(\theta)\right)$ of an individual of type $\theta$ is given by

$$
\begin{aligned}
\text { (i) } \xi^{\circ}(\theta) & =1, \\
\text { (ii) } \tau^{\circ}(\theta) & =\frac{1-\left(\frac{\theta}{\theta_{M}}\right)^{1 / \sigma}}{1 / \sigma} .
\end{aligned}
$$

The striking result is that all individuals prefer full enforcement when they set both the enforcement level and the tax rate simultaneously. The intuition for this result is that less-than-full enforcement is costly for consumers, because it generates tax evasion by firms, and in order to conceal this evasion firms have to incur a cost which is increasing with the amount evaded. Part of this cost is in turn passed through to the price of the good. If voters can control both the tax rate and the enforcement level, they set the effective tax rate at their most-preferred level while ensuring that firms minimize costs by not evading. This is in stark contrast with the situation which obtains when voters only control the enforcement level and allow for evasion as a way to decrease the effective tax rate faced by firms.

As a consequence, the formula for $\tau^{\circ}$ depends only on parameters related to the demand or to the distribution of types, and not to parameters related to evasion, such as the concealment cost $k$. The most-preferred tax rate decreases with $\theta$ for the same reason that $\xi^{*}$ decreases with $\theta$ : consumers with a larger taste for the good consume more of it and are more affected

\footnotetext{
${ }^{13}$ It is straightforward that adding a constant $w$ to the utility of each individual is immaterial when voting upon $\tau$ and $\xi$.

${ }^{14} \mathrm{An}$ intuitive explanation for the existence of a Condorcet winner is that politicians cannot appeal simultaneously to disconnected subsets of the voters' type space, as those types who prefer low enforcement also prefer a low tax rate. Thus, given any two distinct platforms, there would be a cutoff such that all voter types below the cutoff prefer the one candidate, and all types above prefer his opponent. We thank the referee for suggesting this explanation.
} 
by the price increase which follows from an increase in either the tax rate or the enforcement level.

From Proposition 7, we obtain that simultaneous majority voting results in full enforcement together with a tax rate given by (13) where $\theta=\theta_{\text {med }}$. The majority chosen value of $\tau$ is positive provided that the demand of the individual with the median willingness to pay is lower than the average demand -i.e., $\left(\theta_{\text {med }} / \theta_{M}\right)^{1 / \sigma}<1$. In the special case of logarithmic utilities (unitary demand elasticity), $\theta_{M}=\theta_{\mu}$. Hence, the majority chosen value of $\tau$ is positive in that case if $\theta_{\text {med }}<\theta_{\mu}$-i.e., if the distribution of willingness to pay is positively skewed. More generally, numerical simulations (following Assumption 1) suggest that a more positively skewed distribution of $\theta$ increases $\tau^{\circ}\left(\theta_{\text {med }}\right)$. The impact of the demand elasticity is more difficult to assess, since it affects both the numerator and the denominator of $\tau^{\circ}$. Numerical simulations suggest that increasing the demand elasticity $1 / \sigma$ results in a larger value of $\tau^{\circ}\left(\theta_{\text {med }}\right)$.

The analysis contained in section 4 shows that a utilitarian social planner maximizes the utility of type $\theta_{M}$. Applied to (13), we then obtain that the social optimal setting of both $\tau$ and $\xi$ results in a zero tax rate. As in this model there is no revenue requirement for the government, the only reason for a social planner to introduce indirect taxation is to benefit the average consumer with the lump sum transfer. ${ }^{15}$ But the introduction of indirect taxation (starting from $\tau=0$ ) only has second-order effects. These correspond to the first and the third term inside the bracket in equation (20) where $\theta_{\text {med }}$ is replaced by $\theta_{M}$. These two effects have the same magnitude when $\tau=0$ : the increase in the lump sum transfer received is equal to the increase in the expenditures of the individual with the average demand.

We summarize these results in the following proposition:

Proposition 8 With isoelastic utilities, if both the tax rate and the enforcement level are set simultaneously, we obtain that

(i) full enforcement is both optimal and chosen by majority voting,

(ii) the optimal tax rate is zero,

(iii) the majority-chosen tax rate is positive if the median type has a lower than average demand.

\footnotetext{
${ }^{15}$ Recall that our definition of welfare does not include profits. If it were, this would be a further reason not to introduce indirect taxation, since profits are decreasing in $\tau$ with isoleastic demands.
} 
Before concluding, we mention various extensions to our model, and how they would affect our results.

\section{Extensions}

In this section, we come back to three main assumptions of the model (individuals differ in tastes, profits are not distributed to consumers and there is a single consumption good which is taxed) and we mention how our results depend on these assumptions.

We have adopted the industrial organization approach where voters differ in taste rather than the public economics approach where people differ in income. We could reformulate this paper and have income differences replace taste heterogeneity, provided that we move away from quasi-linear preferences to a demand increasing monotonically with income. The main results of our positive analysis above would remain unchanged, with the majority chosen enforcement level increasing with the skewness of the income distribution. ${ }^{16}$ This result is reminiscent of the literature on the political economy of income taxation, which finds that the equilibrium tax rate increases with the gap between median and average income. Unfortunately, this testable implication has by and large been refuted by the empirical literature. Moreover, this approach would not allow us to compare markets inside the same country.

We now discuss the assumption that profits are only distributed to nonresidents. If profits were distributed to residents, they would be incorporated into the objective of the utilitarian planner. With the isoelastic demands introduced in section 5, a larger enforcement level always decreases firms' profits. Therefore, at the value $\xi^{\text {opt }}$ that we identify above, the derivative of the average welfare would be negative. This in turn means that, provided the planner's objective is concave, the socially optimal enforcement level is lower than $\xi^{o p t}$ previously identified. While the optimal enforcement level does not depend on the identity of the citizens who own the shares, the majoritychosen level does depend on the precise distribution of profits among voters. If the set of voting citizens who own shares of the firms is of zero measure, the analysis contained in section 3.3 remains unchanged, and Proposition 4 is easily modified, with more cases in which the majority-chosen enforcement

\footnotetext{
${ }^{16}$ The optimal determination of the enforcement level would be influenced by a redistributive motive and would differ from section 4 .
} 
level is larger than the socially optimal one. If the set of capitalists has positive measure, the previous analysis does not hold since individual preferences generically do not satisfy the single-crossing property anymore.

In order to deal with this issue, we have to introduce a second dimension of heterogeneity among voters, namely the fraction of firms' profits that each one is entitled to. The simplest way to proceed consists in grouping exogenously consumers according to the proportion of firms's shares (and thus profits) that they own -i.e., to consider a setting where the second dimension of heterogeneity takes a finite set of values. In that case, De Donder (2010) shows that, under certain assumptions, a Condorcet winning enforcement level exists, but that the decisive voter is no longer the individual with the median taste for the good in the whole society. Since any consumer owning a positive share of firms' profits has a lower preference for tax enforcement than if he owned no share, the Condorcet winning enforcement level can not be larger than when the set of consumers who own firms' shares has zero measure. A more precise statement would require specific assumptions on how profits are distributed and would essentially be a numerical exercise that we leave for future research.

Finally, we have concentrated here on a single market. This allows us to assess which variables determine the extent of the enforcement level on this generic market. Another approach would consist in modelling several interacting markets from the outset. Doing so would however seriously complicate the analysis. Indeed, individuals' demand for each good generally depends on other goods prices and thus other goods enforcement levels. As a result, the price cost margin as given by the right-hand side of equation (4) would no longer be constant since the elasticity of demand in a particular market would depend upon the enforcement level adopted in every markets. Our general results however still hold if the elasticity of demand in a particular market is independent of other goods' prices. Our general results are still valid with $I$ interacting markets if $(i)$ preferences can be represented by CES utility functions of the form $u(q)=\theta q$ where $q=\left(\sum_{i}^{I} q_{i}^{\rho}\right)^{1 / \rho}$ and $(i i) I$ is large enough. In this case, as shown by Dixit and Stiglitz (1977), the elasticity of demand in the market of good $i$ only depends upon $\rho$ and equation (4) is still valid, with $\eta$ being a constant. 


\section{Conclusion}

This paper has started from the observation that the enforcement of indirect taxation varies across countries and across markets. In order to explain the determinants of tax enforcement, we build a model where individuals vote over the enforcement level anticipating how the market equilibrium is affected by their choice. As we want to explain the emergence of low equilibrium enforcement, we bias the model in favor of enforcement by assuming that tax audits are costless and perfect (i.e., that they always reveal correctly whether a firm has cheated or not, and how much). Voters differ in their willingness to pay for the taxed good and face the following trade-off: more enforcement increases tax collection but also increases the consumer price of the good sold in an imperfectly competitive market.

Our focus is the enforcement level so that we assume in most of the paper that the tax rate is set at an exogenous level. We show that there exists a Condorcet winning enforcement level -i.e., an enforcement level preferred by a majority of voters to any other enforcement level. This level corresponds to the one most-preferred by the individual with the median willingness to pay. We show that this level is affected neither by the structure of the market (the number of firms) nor by firms' marginal cost. Interestingly, this means that our analysis remains valid whether we consider a perfectly competitive market, a monopoly, or any Cournot situation in between. We show that the majority-chosen enforcement level decreases with the resource cost of tax evasion (i.e., the resources that an evading firm has to employ in order to prevent the tax administration from discovering the cheating even without audits, through a simple cursory examination), and with the value of the tax rate. We also study how the demand elasticity and the distribution of the willingness to pay affect the equilibrium enforcement level.

In the last section of the paper, we endogenize the tax rate by assuming that individuals vote simultaneously over enforcement level and tax rate. We prove the existence of a Condorcet winning pair of tax rate and enforcement level. This existence result is interesting by itself since simultaneous voting over two dimensions typically fails to generate any Condorcet winner. The reason why such a winner exists in our setting is that individuals differ on only one dimension (their willingness to pay for the taxed good) in such a way that the conflicts between them in the two-dimensional policy space can effectively be reduced to a single dimension. We obtain that, when the tax rate is optimized at the same time as the enforcement level, there is 
full enforcement at the equilibrium, in the sense that no firm evades any tax. In other words, it never pays to let firms evade when both the tax rate and the enforcement level can be simultaneously optimized, because one instrument dominates the other. Of course, this result of full compliance would generalize to maximal compliance if audits were costly or imperfect. For instance, if audits were costly, the equilibrium enforcement level would balance only monetary costs and benefit from audits.

Our main conclusion regarding the existence of markets with low enforcement of indirect taxation is then that this observation crucially depends on the fact that tax rates are not optimized separately on each market. Indeed, in any given country, one observes a very limited number of different tax rates. If tax rates were voted upon or optimized separately on each market, our model predicts that the equilibrium enforcement level on each market would be maximum.

\section{Appendix}

\subsection{Proof of Proposition 2}

Using the inverse demand curve, we have

$$
\frac{\partial p^{*}}{\partial \xi}=p^{* \prime}\left(Q^{*}\right) \sum_{i} \frac{\partial q_{i}^{*}}{\partial \xi}
$$

Recall that optimal individual production decisions are given by the following first-order condition

$$
\underbrace{\left[1-\tau^{e}-g\left(e^{*}\right)\right]\left[p(Q)+p^{\prime}(Q) q_{i}^{*}\right]}_{\Phi\left(q_{i}, \xi\right)}=c .
$$

Applying the implicit function theorem, we obtain

$$
\frac{\partial q_{i}}{\partial \xi}=-\frac{\partial \Phi\left(q_{i}, \xi\right) / \partial \xi}{\partial \Phi\left(q_{i}, \xi\right) / \partial q_{i}}
$$

As $\partial \Phi\left(q_{i}, \xi\right) / \partial q_{i}<0$ by the second-order condition, we have

$$
\operatorname{sign}\left(\partial q_{i} / \partial \xi\right)=\operatorname{sign}\left(\partial \Phi\left(q_{i}, \xi\right) / \partial \xi\right) .
$$


Differentiating $\Phi\left(q_{i}, \xi\right)$ with respect to $\xi$ yields

$$
\frac{\partial \Phi\left(q_{i}, \xi\right)}{\partial \xi}=-\tau e^{*}\left[p^{*}+p^{* \prime}\left(Q^{*}\right) q_{i}^{*}\right]<0
$$

because $p^{*}+p^{* \prime}\left(Q^{*}\right) q_{i}^{*}>0$. Hence $\partial p^{*} / \partial \xi>0$

\subsection{Proof of Proposition 4}

The first-order condition for the optimal tax enforcement level $\xi^{\text {opt }}$ is

$$
\frac{\partial \mathcal{W}}{\partial \xi}=-p^{* \prime}(\xi) Q\left(p^{*}\right)+G^{\prime}(\xi)=0 .
$$

Measuring the derivative of welfare at $\widehat{\xi}$, we obtain that

$$
\frac{\partial \mathcal{W}(\hat{\xi})}{\partial \xi}=-p^{* \prime}(\hat{\xi}) Q\left(p^{*}(\hat{\xi})\right)+G^{\prime}(\hat{\xi})
$$

so that

$$
\frac{\partial \mathcal{W}(\hat{\xi})}{\partial \xi} \lesseqgtr 0 \text { iff } Q\left(p^{*}(\hat{\xi})\right) \gtreqless q_{\theta_{\text {med }}}\left(\left(p^{*}(\hat{\xi})\right)\right) .
$$

Since individual demand is continuously increasing in $\theta$, and since we have a unitary mass of consumers, we denote by $\theta_{M}$ the individual with the average demand at $p(\hat{\xi})$

$$
q_{\theta_{M}}(p(\hat{\xi}))=Q^{*}(p(\hat{\xi})) .
$$

If we assume that the second-order condition

$$
G^{\prime \prime}(\xi)-\left[p^{* \prime}(\xi)\right]^{2} \frac{\partial q_{\theta}\left(p^{*}\right)}{\partial p^{*}}-p^{* \prime \prime}(\xi) q_{\theta}\left(p^{*}\right)<0
$$

is satisfied for all values of $\theta$ (including for $\theta_{M}$ ), we obtain that the function $\mathcal{W}$ is concave in $\xi$, and thus that the proposition holds

\subsection{Isoelastic demand}

With the specification (10), individual demands are of the form

$$
q_{\theta}=\left(\frac{\theta}{p}\right)^{1 / \sigma}
$$


Aggregate demand amounts to

$$
Q(p)=\left(\frac{\theta_{M}}{p}\right)^{1 / \sigma}
$$

where

$$
\theta_{M}=\left(\int \theta^{1 / \sigma} f(\theta) d \theta\right)^{\sigma}
$$

Observe that, with the isoelastic specification, the identity of the individual with the average demand depends only upon the demand elasticity and the distribution of tastes, but not upon the level of enforcement. As before, $e^{*}=\tau(1-\xi) / k$. Therefore, at the second stage, the equilibrium price $p^{*}$ is given by

$$
p^{*}=\frac{\tilde{c}}{1-\frac{\sigma}{n}},
$$

where $\tilde{c}$ is given by (5) and can be expressed as

$$
\tilde{c}=\frac{c}{1-\tau+\frac{\tau^{2}(1-\xi)^{2}}{2 k}} .
$$

The second-order condition for individual profit-maximization in the Cournot stage is satisfied provided $1 / \sigma>1 / n$. For the monopoly case, this is the well known condition that elasticity should be larger than one. As the number of firms increases, the range of admissible values of elasticities increases.

\subsection{Proof of Proposition 5}

Let us rewrite $\widehat{\xi}$ as

$$
\widehat{\xi}=1-\sqrt{\frac{k\left[\left(\theta_{\text {med }} / \theta_{M}\right)^{1 / \sigma}+\alpha \tau-2\right]}{(\alpha-1) \tau^{2}}} .
$$

where $\alpha=(1+1 / \sigma) \geq 1$. For an interior solution, the following inequality must hold

$$
\frac{(\alpha-1) \tau^{2}}{k}-\alpha \tau>\left(\theta_{\text {med }} / \theta_{M}\right)^{1 / \sigma}-2>-\alpha \tau .
$$


Straightforward differentiation of $\widehat{\xi}$ with respect to $\tau$ leads to

$$
\frac{\partial \widehat{\xi}}{\partial \tau}=\frac{1}{2} \sqrt{\frac{(\alpha-1) \tau^{2}}{k\left[\left(\theta_{\text {med }} / \theta_{M}\right)^{1 / \sigma}+\alpha \tau-2\right]}} \cdot \frac{k \tau\left[\alpha \tau+2\left(\left(\theta_{\text {med }} / \theta_{M}\right)^{1 / \sigma}-2\right)\right]}{(\alpha-1) \tau^{3}}
$$

So that

$$
\operatorname{sign}\left(\frac{\partial \widehat{\xi}}{\partial \tau}\right)=\operatorname{sign}\left(\alpha \tau+2\left(\left(\theta_{\text {med }} / \theta_{M}\right)^{1 / \sigma}-2\right)\right) .
$$

Multiplying both sides of the first inequality in (17) by 2 and rearranging, one gets

$$
\alpha \tau+2\left(\left(\theta_{\text {med }} / \theta_{M}\right)^{1 / \sigma}-2\right)<2 \frac{(\alpha-1)}{k} \tau^{2}-\alpha \tau=\tau\left(2 \frac{(\alpha-1)}{k} \tau-\alpha\right)
$$

which is negative when $\sigma \geq 1, k \geq 1$ and $\tau<1$. Hence, by equation (18), $\partial \widehat{\xi} / \partial \tau<0$

\subsection{Most-preferred pair $(\tau, \xi)$}

The first-order condition for an interior preferred value of $\xi$ is given by

$$
\tau e^{*} p^{*} Q\left(p^{*}\right)\left[2+(1-1 / \sigma) \frac{\tilde{c}}{c} \tau^{e}-\frac{\tilde{c}}{c}\left(\frac{\theta}{\theta_{M}}\right)^{1 / \sigma}\right]=0
$$

while the condition for $\tau$ is

$$
p^{*} Q\left(p^{*}\right)\left(1-e^{*}(1-\xi)\right)\left[\frac{1-2 e^{*}(1-\xi)}{1-e^{*}(1-\xi)}+(1-1 / \sigma) \frac{\tilde{c}}{c} \tau^{e}-\frac{\tilde{c}}{c}\left(\frac{\theta}{\theta_{M}}\right)^{1 / \sigma}\right]=0 .
$$

(i) From the first-order condition for an optimal value of $\tau$ (equation (20)), we have that

$$
\frac{\tilde{c}}{c}\left(\frac{\theta}{\theta_{M}}\right)^{1 / \sigma}=\frac{1-2 e^{*}(1-\xi)}{1-e^{*}(1-\xi)}+(1-1 / \sigma) \frac{\tilde{c}}{c}\left(1-e^{*}(1-\xi)\right) \tau .
$$

Substituting this expression into the first-order condition (19), we obtain

$$
\frac{\partial V(\hat{\tau}(\xi), \xi)}{\partial \xi}=p^{*} \tau e^{*} Q^{*}\left[2+(1-1 / \sigma) \frac{\tilde{c}}{c} \tau^{e}-\frac{1-2 e^{*}(1-\xi)}{1-e^{*}(1-\xi)}-\left(1-e^{*}(1-\xi)\right) \tau(1-1 / \sigma) \frac{\tilde{c}}{c}\right] .
$$


Simplifying and rearranging yields

$$
\frac{\partial V(\hat{\tau}(\xi), \xi)}{\partial \xi}=p^{*} \tau e^{*} Q^{*}\left[1+\frac{e^{*}(1-\xi)}{1-e^{*}(1-\xi)}\right]>0 .
$$

So, at the optimum, $\xi^{\circ}=1$.

(ii) When $\tau^{\circ}$ is positive, $\xi^{\circ}=1$ and thus $e^{*}=0$. Plugging this in (20) and rearranging yields

$$
p^{*} Q\left(p^{*}\right)\left[1+(1-1 / \sigma) \frac{\tau}{1-\tau}-\frac{1}{1-\tau}\left(\frac{\theta}{\theta_{M}}\right)^{1 / \sigma}\right]=0
$$

From this expression, we obtain the explicit solution

$$
\tau^{\circ}=\frac{1-\left(\frac{\theta}{\theta_{M}}\right)^{1 / \sigma}}{1 / \sigma}
$$

\section{References}

[1] AFIP (2008) "Estimación del Incumplimiento del IVA" mimeo AFIP, Buenos Aires.

[2] Allingham, M. and A. Sandmo (1972) "Income Tax Evasion: A Theoretical Analysis" Journal of Public Economics 1, 323-338.

[3] Bayer, R. and F. Cowell (2009) "Tax Compliance and Firms' Strategic Interdependence" Journal of Public Economics 93, 1131-1143.

[4] Borck, R. (2004) "Stricter enforcement may increase tax evasion" European Journal of Political Economy 20, 725-737.

[5] Borck, R. (2007) "Voting, Inequality and Redistribution" Journal of Economic Surveys 21, 90-109.

[6] Borck, R. (2008) "Voting on Redistribution with Tax Evasion" Social Choice and Welfare, forthcoming, DOI 10.1007/s00355-008-0334-8.

[7] Cour des Comptes (2010) "Les méthodes et les résultats du contrôle fiscal" Rapport public annuel, Paris. 
[8] Cremer, H. and F. Gahvari (1993) "Tax evasion and the optimal commodity taxation" Journal of Public Economics 50, 261-275.

[9] De Donder, Ph. (2010) "Majority voting when voters belong to different groups inside which the single crossing property holds" mimeo, Toulouse School of Economics.

[10] Dixit, A. and J. Stiglitz (1977) "Monopolistic Competition and Optimum Product Diversity" American Economic Review 67, 297-308.

[11] European Commission (2009) "Fight against tax fraud: Commission publishes a study on the VAT gap in the EU" IP/09/1655, Brussels. Available at http://europa.eu/rapid/pressReleasesAction.do?reference $=\mathrm{IP} / 09 / 1655$

[12] Gans, J. and M. Smart (1996) "Majority voting with single-crossing preferences" Journal of Public Economics 59, 219-237.

[13] Goerke, L. and M. Runkel (2006) "Profit Tax Evasion under Oligopoly with Endogenous Market Structure" National Tax Journal 59, 851-857.

[14] Goerke, L. and M. Runkel (2011) "Tax Evasion and Competition" Scottish Journal of Political Economy, forthcoming.

[15] Grandmont, J.-M. (1978) "Intermediate preferences and the majority rule" Econometrica 46, 317-330.

[16] Hernández Trillo, F. and A. Zamudio (2004) "Evasión Fiscal en México: El caso del IVA" mimeo, CIDE, Mexico.

[17] Keen, M. and S. Smith (2006) "VAT Fraud and Evasion: What do we know, and What Can be Done?" National Tax Journal 59, 861-887.

[18] Le Breton, M. and F. Salanié (2003) "Lobbying under Political Uncertainty" Journal of Public Economics 87, 2589-2610.

[19] Marelli, M. (1984) "On Indirect Tax Evasion" Journal of Public Economics 25, 181-196.

[20] Marelli, M. and R. Martina (1988) "Tax Evasion and Strategic Behavior of the Firms" Journal of Public Economics 37, 55-69. 
[21] Milgrom, P. and C. Shannon (1994) "Monotone Comparative Statics" Econometrica 62, 157-180.

[22] Nam, C.W., R. Parsche and B. Schaden (2001) "Measurement of the Value Added Tax Evasion in Selected EU Countries on the Basis of National Accounts Data" IFO Studien 2, 127-144.

[23] OECD (2009) "Developments in VAT Compliance Management in Selected Countries", Forum on Tax Administration, Information Note.

[24] Persson, T. and G. Tabellini (2000) Political Economics. Explaining Economic Policy, The MIT Press: Cambridge.

[25] Roine, J. (2003) "Voting over tax schedules in the presence of tax avoidance" Stockholm School of Economics Working Paper Series in Economics and Finance $n^{\circ} 529$.

[26] Roine, J. (2006) "The political economics of not paying taxes" Public Choice 126, 107-134.

[27] Sandmo, A. (2005) "The Theory of Tax Evasion: A Retrospective View" National Tax Journal 58, 643-663.

[28] Skinner, J. and J. Slemrod (1985) "An Economic Perspective on Tax Evasion" National Tax Journal 38, 345-353.

[29] Superintendencia de Administración Tributaria (2007) "El Nivel de Incumplimiento del Impuesto al Valor Agregado, 2005 y 2006" mimeo, SAT, Guatemala.

[30] Traxler, C. (2006) "Voting over Taxes: The Case of Tax Evasion" University of Munich Discussion Papers in Economics 2006-27.

[31] Virmani, A. (1989) "Indirect Tax Evasion and Product Efficiency" Journal of Public Economics 39, 223-237.

[32] Vives, X. (1999) Oligopoly Pricing, The MIT Press: Cambridge.

[33] Wang, L. and J. Conant (1988) "Corporate Tax Evasion and Output Decisions of the Uncertain Monopolist" National Tax Journal 41, 579581. 
[34] Yaniv, G. (1995) "A Note on the Tax Evading Firm" National Tax Journal 48, 113-120. 